\section{Review and}

\section{Technical Note}

\author{
Corresponding Author \\ Ralf Wagner \\ (iD https://orcid.org/0000-0003-0308-1072 \\ Ligamenta Spine Center, Walter-Kolb- \\ Straße 9-11, 60594 Frankfurt, Germany \\ E-mail:w_ralf@hotmail.com
}

Received: February 28, 2020

Revised: May 20, 2020

Accepted: May 29, 2020

\section{(c) (i) (8)}

This is an Open Access article distributed under the terms of the Creative Commons Attribution Non-Commercial License (https://creativecommons.org/licenses/by-nc/4.0/) which permits unrestricted non-commercial use, distribution, and reproduction in any medium, provided the original work is properly cited.

Copyright (c) 2020 by the Korean Spinal Neurosurgery Society

\title{
Uniportal Endoscopic Lumbar Interbody Fusion
}

\author{
Ralf Wagner ${ }^{1}$, Monika Haefner ${ }^{2}$ \\ ${ }^{1}$ Ligamenta Spine Center, Frankfurt, Germany \\ ${ }^{2}$ Endoscopic Spine Experts, Joimax GmbH, Karlsruhe, Germany
}

The cause of radiculopathy is the compression of the nerve root which can be secondary to sliding of the vertebra and reduced disc height. In some patients, decompression alone does not resolve this problem. We describe the uniportal endoscopic transforaminal lumbar interbody fusion technique. Full-endocopic foraminotomy and discectomy are followed by cage implementation and percutaneous instrumentation. The goal of this surgical method is decompression of nerve roots, segment stabilization, disc height, and sagittal alignment restoration. Uniportal endoscopic facet sparing transforaminal transkambin lumbar interbody fusion is a good surgical option to treat degenerative disc disease, mechanical instability, and spondylolisthesis. This method shows favourable clinical outcomes in selected patients.

Keywords: Lumbar interbody fusion, Endoscopic interbody fusion, Surgical technique, Spinal stenosis, Decompression, Transforaminal endoscopy

\section{INTRODUCTION}

Transforaminal transkambin interbody fusion is a routinely used and well-accepted technique for lumbar fusion. Goals of the transforaminal lumbar interbody fusion (TLIF) are the decompression of central canal stenosis or exiting nerve roots, enlargement of the neuroforamina through disc height restoration, segment stabilization, and sagittal alignment restoration with an appropriate anterior load bearing.

Conventional TLIF has drawbacks due to long skin incision, muscle stripping, epidural fibrosis, blood loss, and possible nerve root injury. Minimally invasive tissue-sparing approaches became the standard in many areas and are preferred over traditional open surgery in both hospitals and ambulatory surgery centers. Reduced destruction of soft tissue results in reduced postoperative pain and length of hospital stay..$^{1-3}$ Despite many advantages, the learning curve especially in endoscopic procedures is a frequently discussed issue. ${ }^{4-7}$

The use of full-endoscopic uniportal or biportal techniques with a rigid endoscope is becoming more popular for decompression of central and lateral recess stenosis. ${ }^{8-13}$

The tranforaminal region (Kambin triangle) is the key for the transforaminal fusion techniques as it defines the point of entry. The endoscopic transforaminal approach can potentially reduce the risk of uncontrolled bleeding, excessive blood loss, and the need for blood transfusion. The disc height determines the cranial and caudal dimension of the neuroforamen. Length of the pedicle, facet joint arthritis, and hypertrophic yellow ligament influence the size of the Kambin triangle.

Spinal stenosis, disc protrusion, or herniations as well as osteophytes on the endplates of the motion segment can cause a change in position of the neural structures. The traversing nerve root might be shifted anteriorly in spinal stenosis. In case of herniated discs, the exiting nerve root can be pushed to posterior, medial or lateral, depending on the location of the extruded disc material.

Wang et al. ${ }^{14}$ report on an effective and safe transforaminal approach utilizing the endoscope to implant an expandable cage. 
The disc space was filled with bone graft and percutaneous screw fixation was performed under local anesthesia. The use of conscious sedation allows for live neurological monitoring through patient's feedback.

Critical steps of endoscopic fusion are the avoidance of exiting nerve root injury, preparation of the foramen, decompression of the spinal canal, removal of disc material, and preparation of the endplates. ${ }^{15}$ The fusion rate with or without the use of additional bone substitute as well as the prompt postoperative stability appears to be essential and depend on implant design as well as on the technical steps of the surgery.

In order to restrict the rising costs in health care systems short hospital stays and less use of morphines are encouraged in the postoperative care of lumbar fusion patients. ${ }^{14}$

\section{MATERIALS AND METHODS}

To accomplish a TLIF, first decompression and cage insertion are performed endoscopically. Thereafter screws and rods are implanted percutaneously.

Different types of endoscopic TLIFs are described in the literature. There are uni- and biportal techniques as well as mi- croendoscopic methods. ${ }^{15-20}$ The following surgical technique describes a uniportal endoscopic transforaminal TLIF procedure as it is used by the author.

Surgical technique TLIF procedure (steps 1-8)

\section{Full-Endoscopic Foraminotomy and Discectomy (Steps 1-4)}

\section{Step 1. Preoperative preparation and set-up}

Patient selection is an important factor in terms of surgical success, which is why all necessary diagnostic measures must be carried out first. In most cases, radiological imaging with $\mathrm{x}$ ray and magnetic resonance imaging (MRI) is sufficient for diagnosis. Additional computed tomography scans as well as functional $\mathrm{x}$-rays are sometimes necessary to assess disc calcification, bone formation, and stability.

The operating room should provide the surgeon with sufficient space to perform the procedure and the possibility to limit the radiation exposure. The surgery room should be large enough to accommodate the endoscopic tower, C-arm, operation table, and instrument tables. The surgeon stands on the opposite site of the $\mathrm{C}$-arm, the endoscopic tower is positioned at the foot of the patient (Fig. 1A).

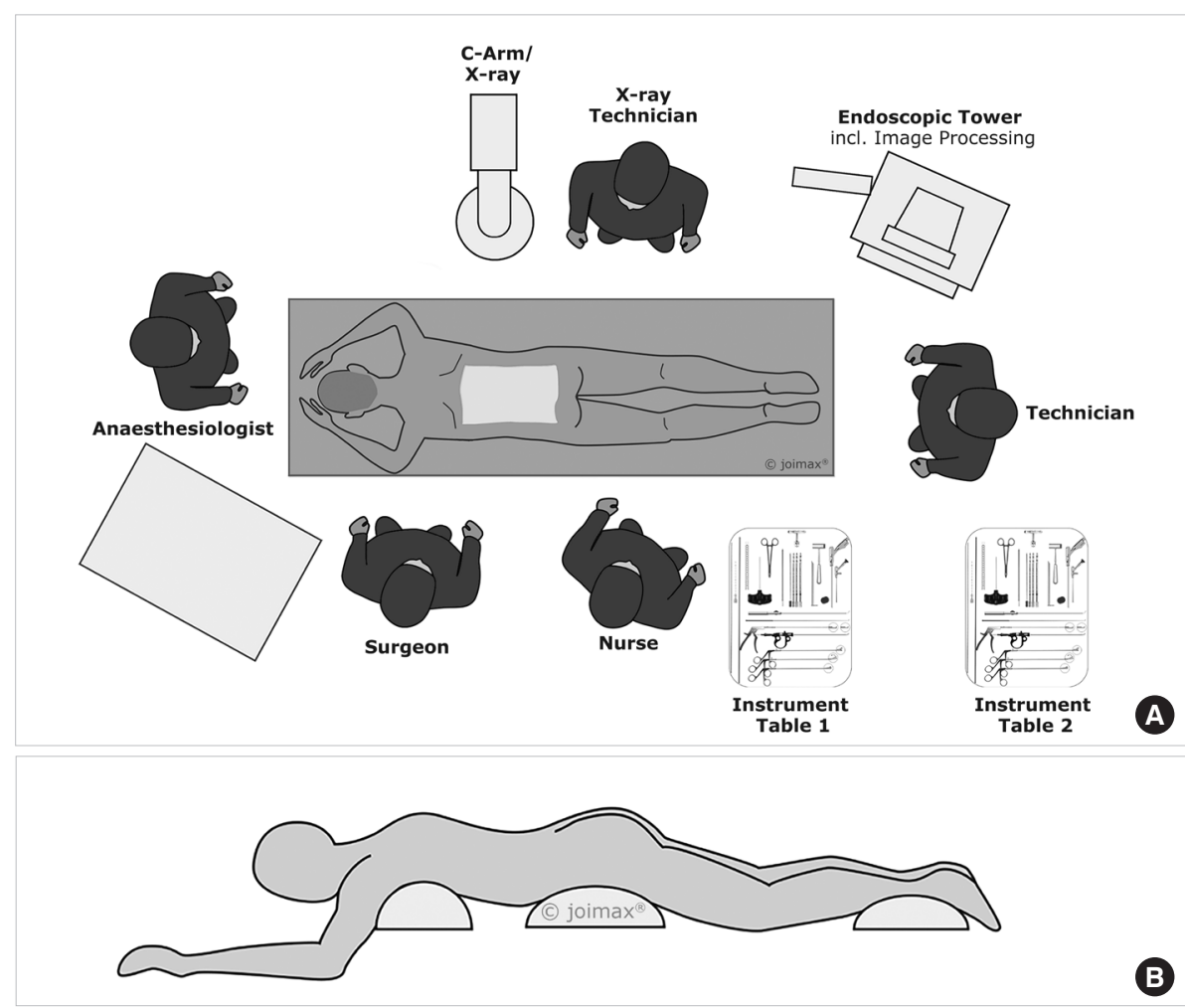

Fig. 1. (A) Surgery set-up. (B) Prone position with positioning cushion. 


\section{Step 2. Anesthesia and patient positioning}

The procedure can be performed under local anesthesia with the patient in prone position. A possible scheme for conscious sedation is a combination of Midazolam, Remifentanil plus oxygen via nasal cannula. The drugs are dosed individually by titration and also based on the different stages of intervention. The author prefers general anesthesia without (long lasting) muscle relaxants. Two cushions under chest and hip of the patient or a Wilson frame help to achieve less lordosis of the lumbar spine. At the same time, the pressure is taken away from the inner organs, reducing the risk of epidural vein bleeding (Fig. $1 \mathrm{~A}, \mathrm{~B})$.

\section{Step 3. Approach planning}

First, the spinous process line, the iliac crest line, pedicular line, and the correct intervertebral disc space are marked. Then the pedicles of the cranial and caudal vertebra are identified and marked to faciliate the later screw placement (Fig. 2A-C).

Depending on the pathology the first step of the surgery might be the screw placement and possible distraction or reduction of spondylolisthesis. Disadvantages of starting with screw placement are less haptic feedback when determining the final implant size due to ligamentotaxis and a lower quality of intraoperative fluoroscopy.

\section{Step 4. Endosopic procedure (Supplementary video clip 1)}

The incision should be performed on the clinically symptomatic side. In case of scoliotic deformity, an incision on the convex side of scoliosis could offer the advantages of a larger neuroforamen and more medial position of the traversing nerve root and dural sack.

The entry and incision point are about $8 \mathrm{~cm}$ (in most patients between 7 to $9 \mathrm{~cm}$ ) off the spinous process line depending upon the level of fusion. The needle trajectory ranges from $40^{\circ}-50^{\circ}$. The target point of the procedure is the center of the disc space into which the implant is inserted. The trajectory should be parallel to the disc space.

A clear anteroposterior (AP) and lateral $\mathrm{x}$-ray without rotation is the key to an exact entry point determination. The author prefers to change the angulation of the table over changing the rotation or angulation of the fluoroscopy.

The needle is first advanced to the superior articular process (SAP) and then pushed forward to the posterior longitudal ligament. A haptic response is received when reaching the ligament. In the AP image, the needle tip should touch the posterior ligament and be located in the medial half of the interpedicular line. In the lateral $\mathrm{x}$-ray, the needle tip should still be dorsal to the posterior margin of the vertebras. An oblique image can be helpful to target the center of the disc. The optimal angulation should be $45^{\circ}$ to the patient's back (Fig. 3). Then the needle is advanced

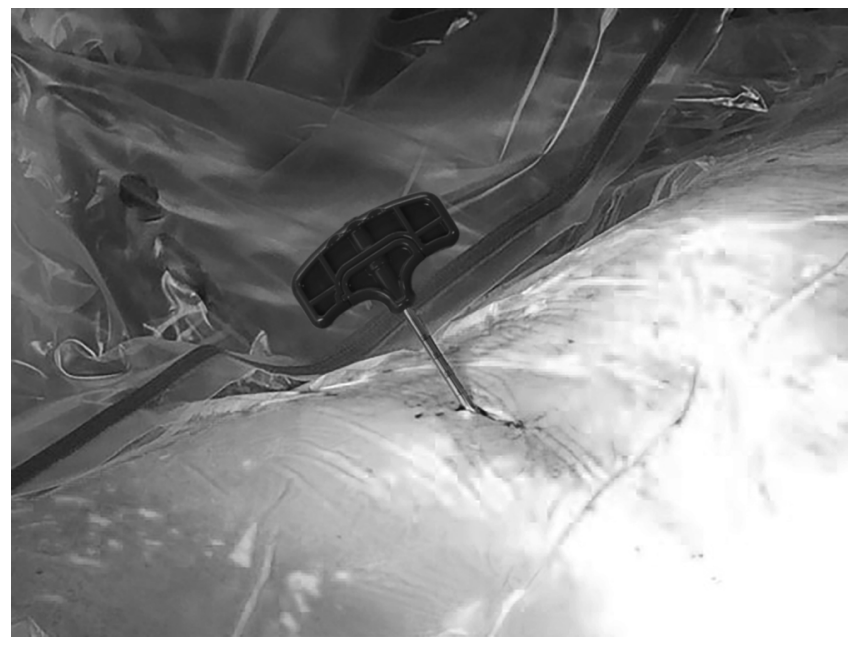

Fig. 3. Position of the needle at a $45^{\circ}$ angle.
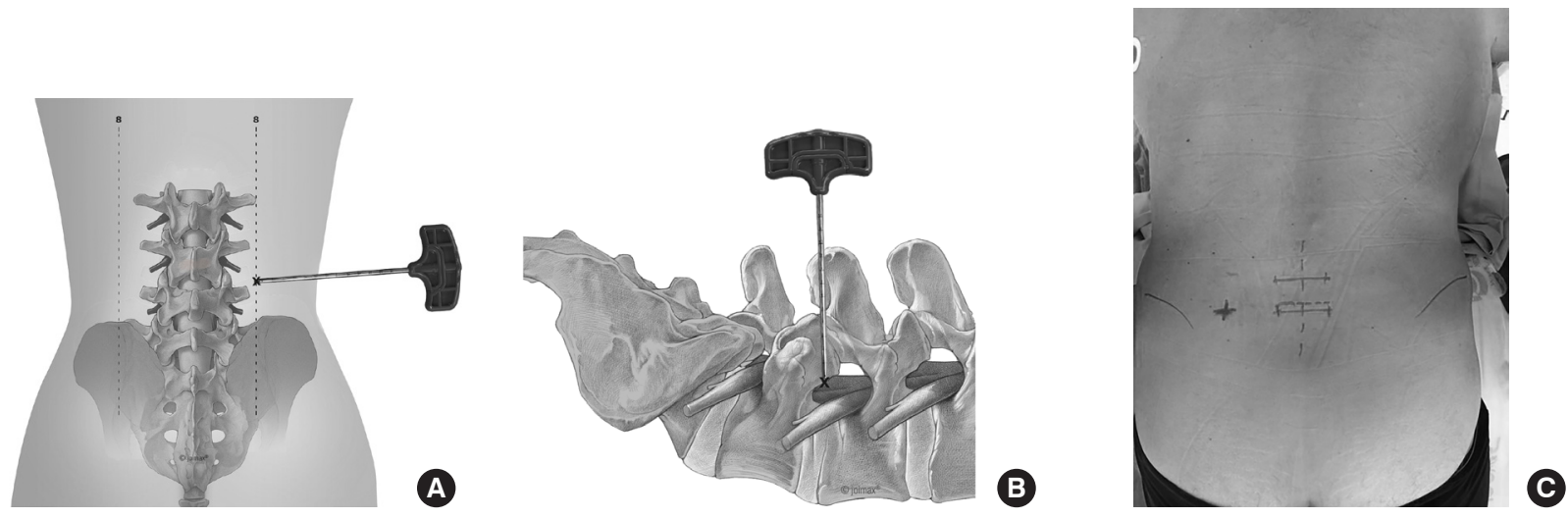

Fig. 2. (A) Approach planning. (B) Approach lateral view. (C) Skin marking. 
to the center of the disc under radiological control in AP (Fig. $4 \mathrm{~A})$ and lateral views. The approach is comparable to a discogram - without compromising the parallel placement of the needle to the upper and lower endplate of the disc space. Additionally, methylen blue in combination with radio-opaque contrast fluid can be used to perform a discogram and color the disc.

The guidewire is inserted. The skin and lumbar fascia are incised. In the case of limited space in the neuroforamen, a Jamshidi needle is helpful to perform a trans-SAP approach for a controlled foraminotomy without increased risk of exiting nerve root compromise.

The aim is the anatomical restoration of the neuroforamen by foraminoplasty to create space for the final implant.

The bone drills are used in a small to large diameter sequence
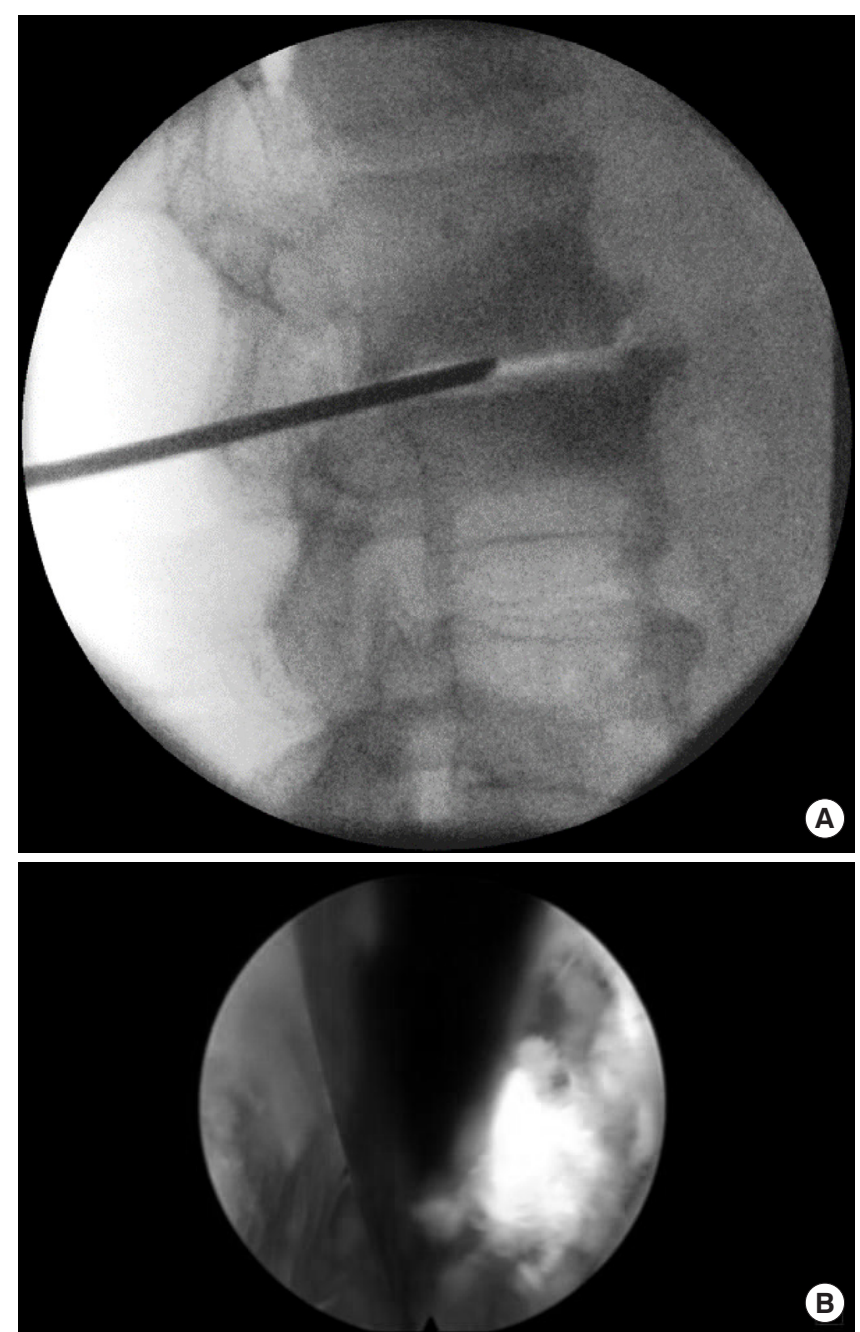

Fig. 4. (A) Placement of the needle parallel to the upper and lower endplate at the center of the disc. (B) Intraoperative placement of Kirschner wire. to prepare the endplates (Fig. 5A, B). The reaming is done under fluoroscopic guidance. The fluoroscopic control also prevents end plate damage by confirming the correct drill bit diameter corresponding to the hight of the intervertebral disc space. Iatrogenic damage is also prevented by the design of the drill itself. A thorough preparation of the end plate up to the spongiosa is important. This step already allows to estimate the final dimensions of the interbody implant.

The guiding rod and dilators are then advanced over the guidewire into the foramen, followed by the working tube for the endoscope. After removal of the instruments, the endoscope is
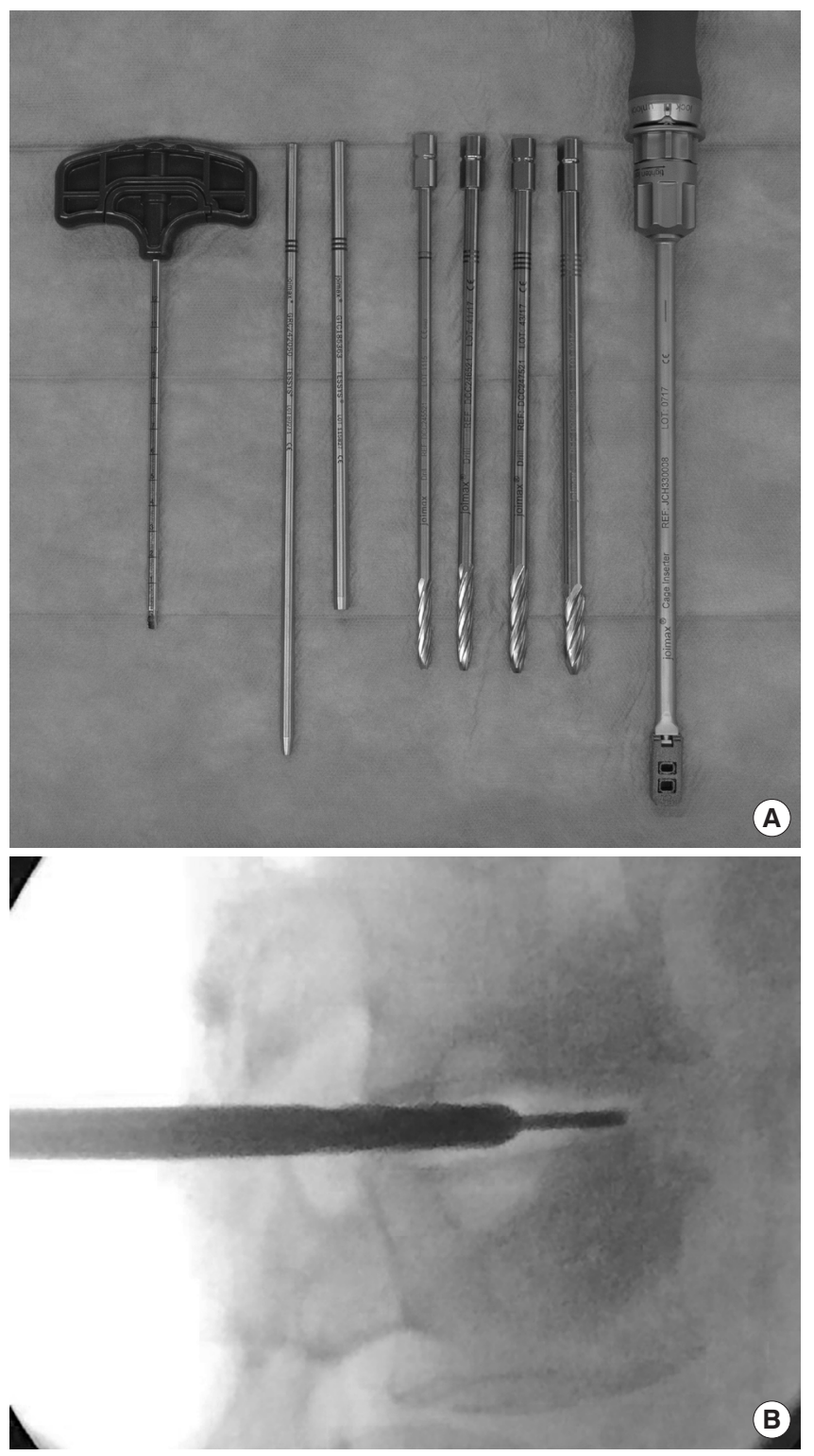

Fig. 5. (A) Dilators, drills, and Jamshidi needle. (B) Use of the drill. 
inserted into the working tube. Disc material is removed and the endplates are inspected. Alternatively to the drills, currettes and spoons can be used to prepare the endplates under fluoroscopic control.

Then the endoscope is retracted together with the working tube to inspect the foraminal area. The upper part of the pedicle as well as the SAP are identified and prepared for foraminoplasty. Next, the traversing nerve root is identified and decompressed. For decompression, the foramen is widened with an endoscopic diamond burr. Then the endoscope is turned towards cranial to identify the exiting nerve root, followed by turning it to inspect and decompress the extraforaminal region. Then the endoscope is rotated back to identify the area of the superior facet, pedicle, and traversing nerve root (so-called arch) and entry to the disc space.

Under visual control, the guidewire is reinserted through the endoscope (Fig. 6A, B) close to the exiting nerve root. Its final postion is controlled with AP and lateral $\mathrm{x}$-ray. The final size of the implant is then determined by using the endplate raspatories and trial implants.

\section{Cage Insertion, Endoscopic Control, and Percutaneous Instrumentation (Steps 5-7)}

\section{Steps 5. Cage insertion}

Finally, the cage with or without bone subtitute is mounted on the cage inserter. It is advanced over the guidewire and can be hammered into the disc space under AP and lateral x-ray control. The final position should be in the center of the disc space in both projections. The cage can then be released and the instrument removed. During this step, a parallel position of the cage should be achieved and confirmed by the AP and lateral X-ray (Fig. 7A-E).

The guiding rod, working tube, and endsocope are consecutively inserted and remaining tissue is removed from the foraminal area, allowing a postcage placement view on the implant, traversing nerve as well as exiting nerve root.

\section{Steps 6. Instrumentation}

Under fluoroscopic guidance, the pedicles are identified. After inserting the pedicle probe to obtain a perfect intrapedicular placement, the pedicle holes are tapped. The appropiate sized pedicle screws are then placed under fluoroscopic guidance and their position controlled in AP and lateral x-ray images. The rods are inserted after measuring their required length with the measurement tool. Finally, the screws are tightened and the tulips (tabs) are removed.

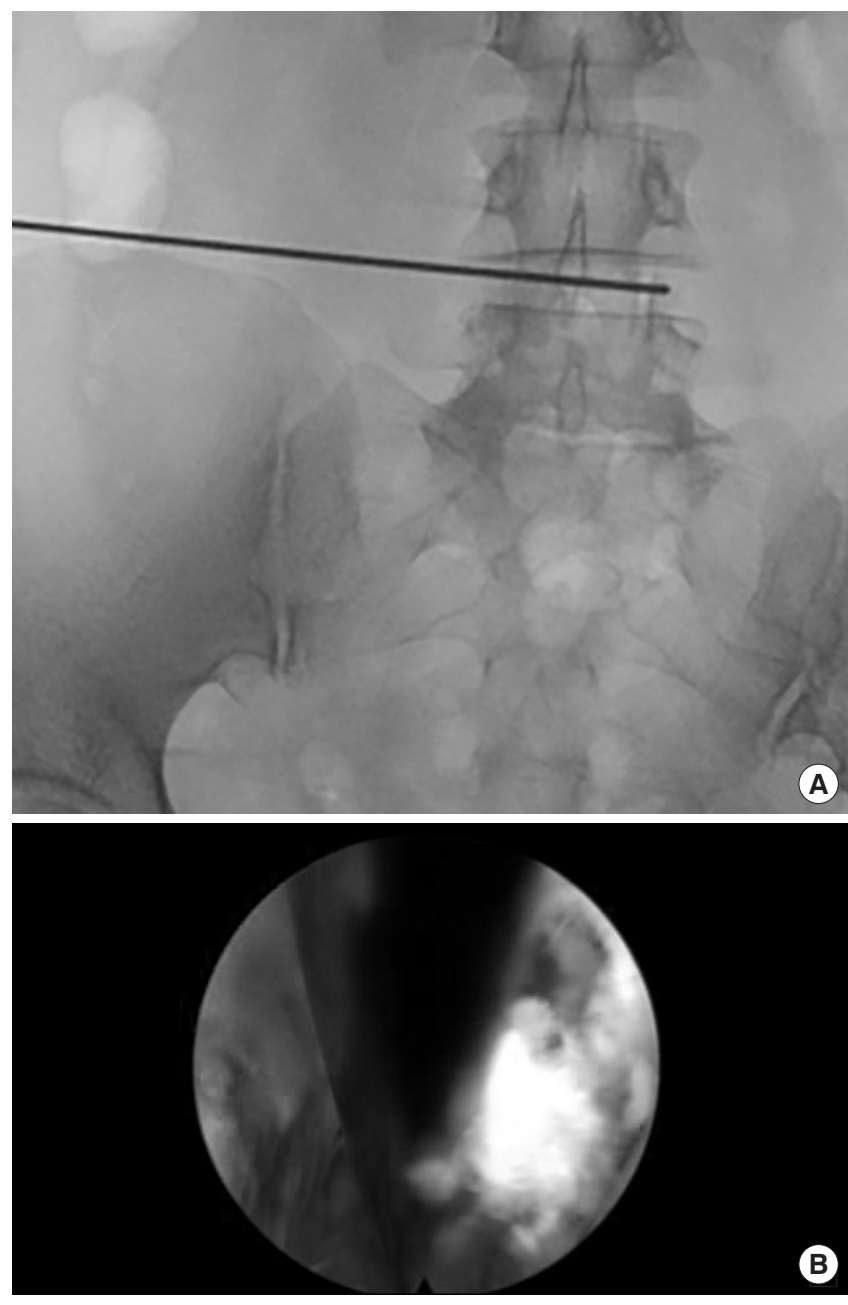

Fig. 6. (A) Reinsertion of guidewire. (B) Endoscopic view guidewire.

Final $\mathrm{X}$-rays should then be performed in both views lateral and AP (Fig. 8A, B).

\section{Steps 7. Surgical site management}

Constant saline irrigation is used during the endoscopic procedure not only for visualization but also for flushing the surgical site. Intraoperative bleeding can be controlled with the bipolar probe. Usually, a drain is not needed (Fig. 9). When necessary, it can be placed through the working channel of the endsocope, thus avoiding an additional incision. The fascia and skin are closed with 3-4 single sutures.

\section{Postoperative Care (Step 8)}

\section{Steps 8. Postoperative care}

Patients routinely receive a single dose of antibiotics (lasting for 5-7 days), unless there is an increased risk of infection. Glu- 

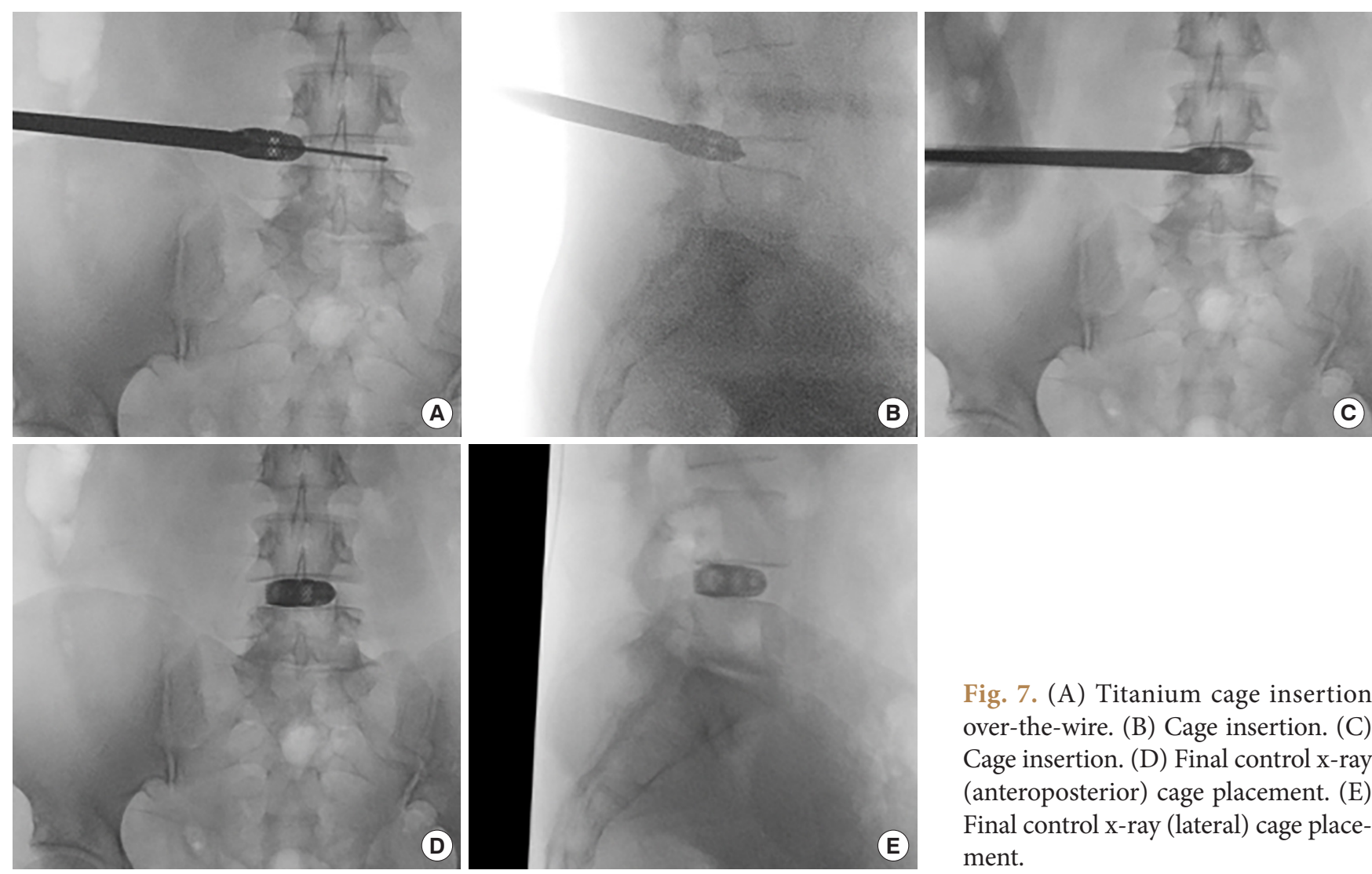

Fig. 7. (A) Titanium cage insertion over-the-wire. (B) Cage insertion. (C) Cage insertion. (D) Final control x-ray (anteroposterior) cage placement. (E) Final control x-ray (lateral) cage placement.
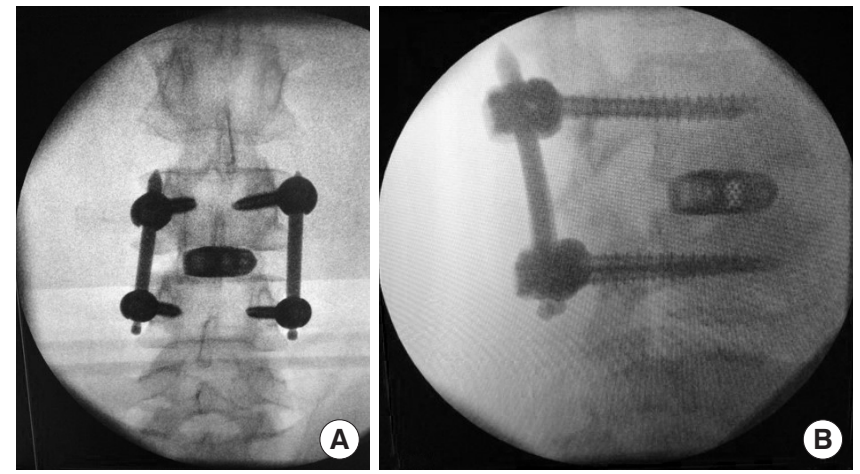

Fig. 8. (A) Final control x-ray (anteroposterior). (B) Final control x-ray (lateral).

cocorticoids (8-mg dexamethasone) are administered orally on the day of surgery and in case of postoperative leg symptoms in decreasing doses for 9 days (8 $\mathrm{mg}$ on days $1-3,4 \mathrm{mg}$ on days 4-6, $2 \mathrm{mg}$ on days 7-9). However, postoperative dysethesia is rarely seen. Patients are encouraged to do some light activities with a lumbar orthesis in the first 3 weeks postoperative and receive physiotherapy in weeks 3 to 6 , starting with isometric and then biplanar exercises. Excessive and heavy activities should be prohibited for the first 3 months postoperative. A control $\mathrm{x}$ ray after 3 months is recommended.

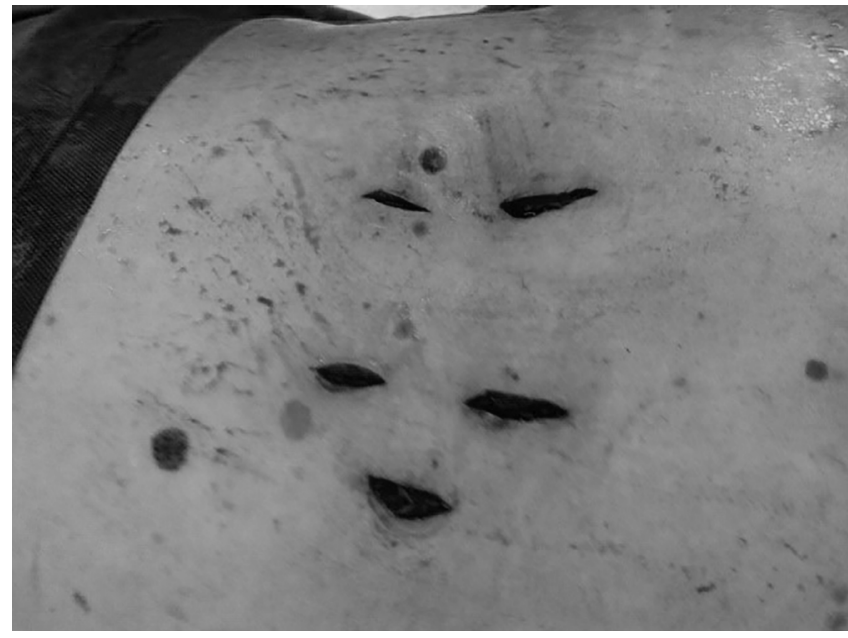

Fig. 9. Size of skin incisions at the end of surgery.

\section{DISCUSSION}

The endoscopic approach for TLIF is a well-known procedure in full-endoscopic spine surgery.

Complications related to interbody fusion surgery can include dural tear, nerve root injury, postoperative hematoma, motor weakness, temporary dysesthesia as well as infection. A sum- 
Table 1. Clinical results, operative time, complications of selected studies

\begin{tabular}{|c|c|c|c|c|c|c|}
\hline Study & $\begin{array}{l}\text { VAS improve- } \\
\text { ment }(\%)\end{array}$ & $\begin{array}{l}\text { ODI improve- } \\
\text { ment }(\%)\end{array}$ & $\begin{array}{l}\text { Operative } \\
\text { time (min) }\end{array}$ & Complication rate & $\begin{array}{l}\text { Fusion rate } \\
\qquad(\%)\end{array}$ & Surgical technique \\
\hline Shen $^{1} 2019$ & VAS back 78 & 73 & 168 & $0 \%$ & 100 & $\begin{array}{l}18 \text { Patients fully endoscopic forami- } \\
\text { notomy, laminectomy, and transfo- } \\
\text { raminal lumbar interbody fusion } \\
\text { (TLIF) combined with percutaneous } \\
\text { screw fixation. }\end{array}$ \\
\hline $\begin{array}{l}\text { Wu et al. }{ }^{2} \\
2012\end{array}$ & VAS leg 97 & 33.7 & 167.5 & $0 \%$ & 100 & $\begin{array}{l}7 \text { Patients single-level percutaneous } \\
\text { endoscopic lumbar interbody fusion } \\
\text { (PELIF) }\end{array}$ \\
\hline $\begin{array}{l}\text { Schwender } \\
\text { et al. }{ }^{4} 2005\end{array}$ & 70.84 & 69.57 & 240 & $\begin{array}{l}2 \text { Patients required reposi- } \\
\text { tioning of misplaced ped- } \\
\text { icle screws. } \\
2 \text { Patients with radiculopa- } \\
\text { thies resolved with reop- } \\
\text { eration. }\end{array}$ & 100 & 45 Patients minimally invasive TLIF \\
\hline $\begin{array}{l}\text { Lee et al. }{ }^{18} \\
2017\end{array}$ & $\begin{array}{l}\text { VAS back } 54 \\
\text { VAS leg } 72\end{array}$ & 69 & 77 & $\begin{array}{l}1 \text { Nonunion } \\
5 \text { Implant breakages } \\
1 \text { Implant migration }\end{array}$ & 94.5 & $\begin{array}{l}18 \text { Patients percutaneous transforami- } \\
\text { nal endoscopic lumbar interbody } \\
\text { fusion }\end{array}$ \\
\hline $\begin{array}{l}\text { Heo et al. }{ }^{19} \\
2017\end{array}$ & VAS leg 65.65 & 66.25 & 165.8 & $\begin{array}{l}\text { Dural tear in } 2 \text { patients and } \\
\text { postoperative epidural } \\
\text { hematoma in } 3 \text { patients }\end{array}$ & 100 & $\begin{array}{l}69 \text { Patients percutaneous unilateral } \\
\text { biportal endoscopic single-level } \\
\text { lumbar fusion surgery }\end{array}$ \\
\hline $\begin{array}{l}\text { Kamson et al. }{ }^{21} \\
2019\end{array}$ & $\begin{array}{l}\text { VAS back + } \\
\text { leg: signifi- } \\
\text { cant drop }\end{array}$ & - & 247 & $5.88 \%$ & 100 & $\begin{array}{l}85 \text { Patients full-endoscopic minimally } \\
\text { invasive lumbar }\end{array}$ \\
\hline $\begin{array}{r}\text { Morgenstern } \\
\text { et al. }{ }^{24} 2018\end{array}$ & $\begin{array}{l}\text { VAS back } 72 \\
\text { VAS leg } 73.5\end{array}$ & 50.9 & - & $\begin{array}{l}3 \text { Patients with transitory, } \\
\text { ipsilateral dysesthesia. } \\
2 \text { Patients with radiologic } \\
\text { cage subsidence }\end{array}$ & 100 & $\begin{array}{l}16 \text { Patients endoscopy-based, facet- } \\
\text { sparing percutaneous (pTLIF) }\end{array}$ \\
\hline $\begin{array}{l}\text { Wang and } \\
\text { Grossman } \\
2016\end{array}$ & - & 68.4 & 113.5 & None & 100 & $\begin{array}{l}10 \text { Patients endoscopic technique for } \\
\text { interbody fusion combined with } \\
\text { percutaneous screw fixation }\end{array}$ \\
\hline
\end{tabular}

VAS, visual analogue scale; ODI, Oswestry Disability Index.

mary of clinical results, operative time, and complications of selected studies are given in Table 1. Kamson describes his intraoperative complication rate as low as $0 \%$ with a total postoperative complication rate at $5.88 \% .{ }^{21}$ Shen ${ }^{1}$ reports in their case series performing full-endoscopic interbody fusion $0 \%$ complications. Morgenstern and Morgenstern ${ }^{22}$ report no major complications using percutaneous TLIF (pTLIF) with a posterolateral approach. Kolcun et al. ${ }^{23}$ found a $4 \%$ conversion rate without major intraoperative or postoperative complications in patients who underwent minimally invasive transforaminal fusion without general anesthesia. $\mathrm{Ahn}^{3}$ notes that the working tube might cause irritation of the exiting nerve root especially in cases of prolonged surgery time. Furthermore, motor weakness as well as temporary dysesthesia are reported as common endosocopic complications. Lumbar fusion is often associated with adjacent segment degeneration. Many complications are associ- ated with the learning curve of minimally invasive TLIF and endsocopic procedures.

Reduction of neurologic injury can be achieved by conscious sedation, neuromonitoring and avoidance of excessive nerve root retraction. A preoperative MRI is useful to detect anatomical anomalies. Another important key factor is the knowledge of anatomical landmarks. The surgeon must ensure that the exact position of the instruments is known during the entire surgical procedure. This is essential to avoid nerve injury and can prevent insufficient decompression of the spinal nerve root.

The hospitalization time is widely varying between the different methods. Morgenstern and Morgenstern ${ }^{24}$ report for pTLIF a median postoperative time to ambulation of 6 hours and a median postoperative time until hospital discharge of 26 hours. In contrast, MIS TLIF resulted in an ambulation of 3.2 days (1.9) and a mean postoperative time until hospital discharge of 
9.3 days (2.6). Similar results are found by $\operatorname{Shen}^{1}$ with a mean length of hospital stay of 1.2 days.

Appropriate selection of patients and appropriate surgical indication of the procedure might be key factors in obtaining good results. ${ }^{18}$ Osteochondrosis L3/4 and spondylolisthesis $\leq$ grade 2 can be good indications. Important are a thorough end plate preparation and a high primary stability also to avoid implant migration. The author has not observed pseudoarthosis in his experience of about 50 cases. Clear advantages of the full-endoscopic decompression and cage insertion over open or other mimimally invasive surgery methods are demonstrated in clinical studies. Minimal iatrogenic trauma to muscles and stabilizing structures, less blood loss, shorter hospital stay, quick recovery, and fewer complications could be demonstrated. Direct visualization helps preventing nerve root injury and to verify a complete decompression and correct cage placement. ${ }^{1}$

\section{CONCLUSION}

Endoscopic TLIF is a good surgical option to treat patients with degenerative disc disease, mechanical instability and/or spondylolisthesis. It minimizes iatrogenic approach-related injury of the segmental structures including the facet joint and shows favorable clinical outcomes in selected patients.

\section{CONFLICT OF INTEREST}

R. Wagner teaches endoscopic spine surgery for joimax and is joimax Faculty Member. M. Haefner is employee of joimax $\mathrm{GmbH}$.

\section{SUPPLEMENTARY MATERIAL}

Supplementary video clip 1 can be found via https://doi.org/ 10.14245/ns.2040130.065.v.1.

\section{REFERENCES}

1. Shen J. Fully endoscopic lumbar laminectomy and transforaminal lumbar interbody fusion under local anesthesia with conscious sedation: a case series. World Neurosurg 2019; 127:e745-50.

2. Wu J, Liu H, Ao S, et al. Percutaneous endoscopic lumbar interbody fusion: technical note and preliminary clinical experience with 2-year follow-up. Biomed Res Int 2018;2018: 5806037.
3. Ahn Y. Transforaminal percutaneous endoscopic lumbar discectomy: technical tips to prevent complications. Expert Rev Med Devices 2012;9:361-6.

4. Schwender JD, Holly LT, Rouben DP, et al. Minimally invasive transforaminal lumbar interbody fusion (TLIF): technical feasibility and initial results. J Spinal Disord Tech 2005;18 Suppl:S1-6.

5. Isaacs RE, Podichetty VK, Santiago P, et al. Minimally invasive microendoscopy-assisted transforaminal lumbar interbody fusion with instrumentation. J Neurosurg Spine 2005; 3:98-105.

6. Ozgur BM, Yoo K, Rodriguez G, et al. Minimally-invasive technique for transforaminal lumbar interbody fusion (TLIF). Eur Spine J 2005;14:887-94.

7. Holly LT, Schwender JD, Rouben DP, et al. Minimally invasive transforaminal lumbar interbody fusion: indications, technique, and complications. Neurosurg Focus 2006;20:E6.

8. Yue JJ, Long W. Full endoscopic spinal surgery techniques: advancements, indications, and outcomes. Int J Spine Surg 2015;9:17.

9. Gore S, Yeung A. The "inside out" transforaminal technique to treat lumbar spinal pain in an awake and aware patient under local anesthesia: results and a review of the literature. Int J Spine Surg 2014;8:28.

10. Shin SH, Bae JS, Lee SH, et al. Transforaminal endoscopic decompression for lumbar spinal stenosis: a novel surgical technique and clinical outcomes. World Neurosurg 2018; 114:e873-82.

11. Lee CW, Yoon KJ, Jun JH. Percutaneous endoscopic laminotomy with flavectomy by uniportal, unilateral approach for the lumbar canal or lateral recess stenosis. World Neurosurg 2018;113:e129-37.

12. Ruan W, Feng F, Liu Z, et al. Comparison of percutaneous endoscopic lumbar discectomy versus open lumbar microdiscectomy for lumbar disc herniation: a meta-analysis. Int J Surg 2016;31:86-92.

13. Li ZZ, Hou SX, Shang WL, et al. Percutaneous lumbar foraminoplasty and percutaneous endoscopic lumbar decompression for lateral recess stenosis through transforaminal approach: Technique notes and 2 years follow-up. Clin Neurol Neurosurg 2016;143:90-4.

14. Wang MY, Chang HK, Grossman J. Reduced acute care costs with the ERAS ${ }^{\bullet}$ minimally invasive transforaminal lumbar interbody fusion compared with conventional minimally invasive transforaminal lumbar interbody fusion. Neurosurgery 2018;83:827-34. 
15. Ahn Y, Youn MS, Heo DH. Endoscopic transforaminal lumbar interbody fusion: a comprehensive review. Expert Rev Med Devices 2019;16:373-80.

16. Jacquot F, Gastambide D. Percutaneous endoscopic transforaminal lumbar interbody fusion: is it worth it? Int Orthop 2013;37:1507-10.

17. Zhou Y, Zhang C, Wang J, et al. Endoscopic transforaminal lumbar decompression, interbody fusion and pedicle screw fixation-a report of 42 cases. Chin J Traumatol 2008;11:22531.

18. Lee SH, Erken HY, Bae J. Percutaneous transforaminal endoscopic lumbar interbody fusion: clinical and radiological results of mean 46-month follow-up. Biomed Res Int 2017; 2017:3731983.

19. Heo DH, Son SK, Eum JH, et al. Fully endoscopic lumbar interbody fusion using a percutaneous unilateral biportal endoscopic technique: technical note and preliminary clinical results. Neurosurg Focus 2017;43:E8.

20. Youn MS, Shin JK, Goh TS, et al. Full endoscopic lumbar interbody fusion (FELIF): technical note. Eur Spine J 2018; 27:1949-55.
21. Kamson S, Lu D, Sampson PD, et al. Full-endoscopic lumbar fusion outcomes in patients with minimal deformities: a retrospective study of data collected between 2011 and 2015. Pain Physician 2019;22:75-88.

22. Morgenstern R, Morgenstern C. Percutaneous transforaminal lumbar interbody fusion (pTLIF) with a posterolateral approach for the treatment of denegerative disk disease: feasibility and preliminary results. Int J Spine Surg 2015;9:41.

23. Kolcun JPG, Brusko GD, Wang MY. Endoscopic transforaminal lumbar interbody fusion without general anesthesia: technical innovations and outcomes. Ann Transl Med 2019;7 (Suppl 5):S167.

24. Morgenstern R, Morgenstern C. Feasibility of full percutaneous segmental stabilization of the lumbar spine with a combination of an expandable interbody cage and an interspinous spacer: preliminary results. Int J Spine Surg 2018;12: 665-72.

25. Wang MY, Grossman J. Endoscopic minimally invasive transforaminal interbody fusion without general anesthesia: initial clinical experience with 1-year follow-up. Neurosurg Focus 2016;40:E13. 